\title{
Catalyst Enhanced by Controlling Structure and Shape of Nanocrystals, Support Materials, and Hybrid System in DMFCs
}

\author{
Young Wook Lee ${ }^{\dagger}$ and Tae Ho Shin
}

Korea Institute of Ceramic Engineering and Technology, Jinju 52851, Korea

\section{나노입자의 구조와 모양, 담지체 및 하이브리드 시스템 제어를 통한 직접메탄올 연료전지의 촉매 개발}

\author{
이영욱 ${ }^{\dagger}$, 신태호 \\ 한국세라믹기술원
}

(Received June 16, 2019; Revised June 24, 2019; Accepted June 24, 2019)

\begin{abstract}
s
Direct methanol fuel cells (DMFCs) have found a wide variety of commercial applications such as portable computer and mobile phone. In a fuel cell, the catalysts have an important role and durability and efficiency are determined by the ability of the catalyst. The activity of the catalyst is determined by the structure and shape control of the nanoparticles and the dispersion of the nanoparticles and application system. The surface energy of nanoparticles determines the activity by shape control and the nanostructure is determined by the ratio of bi- and tri-metals in the alloy and core-shell. The dispersion of nanoparticles depends on the type of support such as carbon, graphen and metal oxide. In addition, a hybrid system using both optical and electrochemical device has been developed recently.
\end{abstract}

Keywords: DMFC, Electorcatalysis, Support matrials, Alloy, Nanosturucture, Shape control, Hybrid systm

\section{1. 서론}

화석연료 에너지자원의 고갈과 화석연료에서 배출되 는 부가물에 의해 기후변화 문제가 대두되고 있으며, 이 에 환경친화적 에너지들이 개발되고 있다. 수소연료전 지, 고체연료전지 그리고 액체 연료 전지등 여러 가지 공
해가 없는 에너지가 개발되고 있으며, 이러한 에너지를 효율과 내구성을 향상하기 위해 노력하고 있다. 중에서도 직접 메탄올 연료전지(DMFCs)는 이산화탄소 배출을 낮 추며, 휴대용 전자기기에 사용할 수 있는 에너지로 대두 되고 있다. 에너지 대한대응책 마련이 범세계적 차원의 해결과제로 대두되어 세계 각국은 에너지 절약 및 친환경 


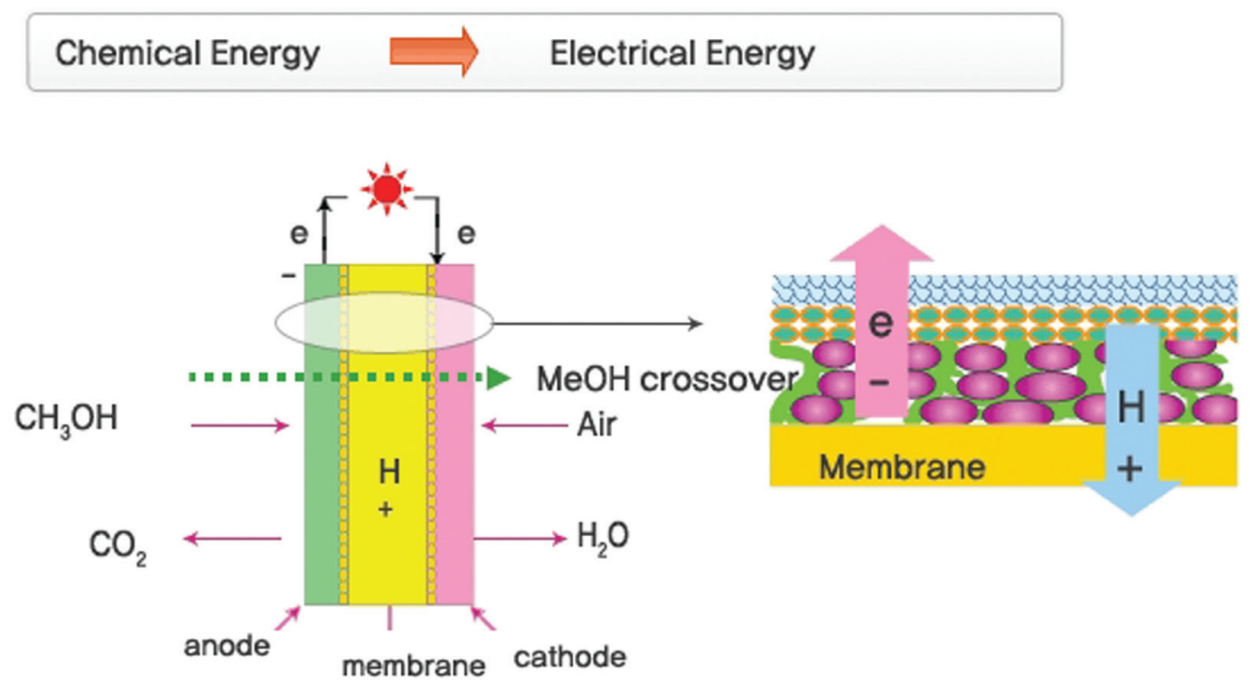

$$
\begin{aligned}
& \text { Anode : } \mathrm{CH}_{3} \mathrm{OH}+\mathrm{H}_{2} \mathrm{O}=\mathrm{CO}_{2}+6 \mathrm{H}^{+}+6 \mathrm{e}^{-} \\
& \text {Cathode : } 1.5 \mathrm{O}_{2}+6 \mathrm{H}^{+}+6 \mathrm{e}^{-}=3 \mathrm{H}_{2} \mathrm{O} \\
& \text { Overall : } \mathrm{CH}_{3} \mathrm{OH}+1.5 \mathrm{O}_{2}=\mathrm{CO}_{2}+2 \mathrm{H}_{2} \mathrm{O}, \mathrm{EO}=1.18 \mathrm{~V}
\end{aligned}
$$

Fig. 1. DMFC의 원리 및 화학반응식

\section{Methanol Oxidation Pathways \\ <Dual-path mechnism>}

1. Non-CO reactive intermediates

\section{Adsorbed $\mathrm{CO}\left(\mathrm{CO}_{\mathrm{ad}}\right)$}

(1) $\mathrm{CH}_{3} \mathrm{OH}+\mathrm{Pt} \rightarrow \mathrm{Pt}-\mathrm{CH}_{2} \mathrm{OH}+\mathrm{H}^{+}+\mathrm{e}$

(2) $\mathrm{Pt}-\mathrm{CH}_{2} \mathrm{OH}+\mathrm{Pt} \rightarrow \mathrm{Pt}-\mathrm{CHOH}+\mathrm{H}^{+}+\mathrm{e}^{-}$

(3) $\mathrm{Pt}-\mathrm{CHOH}+\mathrm{Pt} \rightarrow \mathrm{PtCHO}+\mathrm{H}^{+}+\mathrm{e}^{-}$

(4) $\mathrm{PtCHO} \rightarrow \mathrm{Pt} \mathrm{C} \equiv \mathrm{O}+\mathrm{H}^{+}+\mathrm{e}^{-}$ $\stackrel{\text { or }}{\mathrm{PtCHO}}+\mathrm{Pt} \rightarrow \rightarrow_{\mathrm{Pt}}^{\mathrm{Pt}}>\mathrm{C}=\mathrm{O}+\mathrm{H}^{+}+\mathrm{e}-$

(5) $\mathrm{Pt}+\mathrm{H}_{2} \mathrm{O} \rightarrow \mathrm{PtOH}+\mathrm{H}^{+}+\mathrm{e}^{-}$

(6) $\mathrm{PtOH}+\mathrm{PtCO} \rightarrow 2 \mathrm{Pt}+\mathrm{CO}_{2}+\mathrm{H}^{+}+\mathrm{e}^{-}$

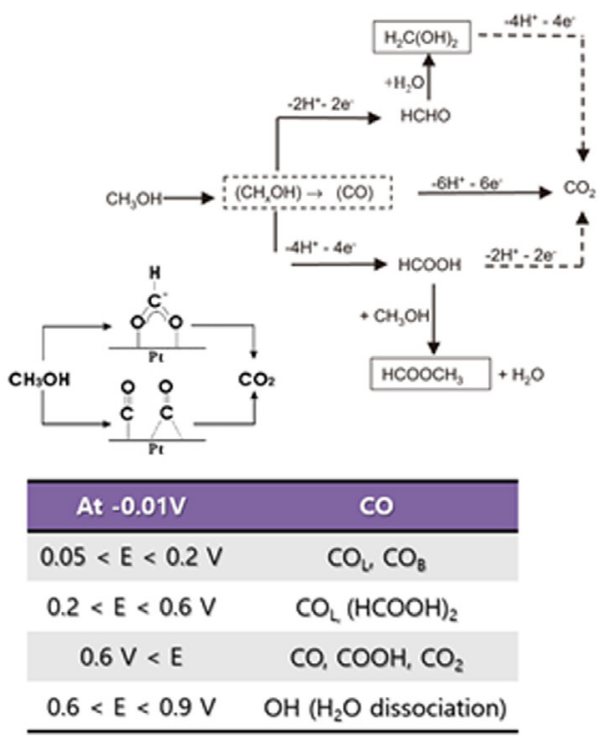

Fig. 2. 백금 나노 촉매와 메탄올 분해과정 메카니즘. ${ }^{6-7)}$

에너지 기술개발 등을 통한 이산화탄소 배출 절감에 커다 란 노력을 기울이고 있다. ${ }^{1-5)}$ 직접 메탄올 연료전지 (direct methanol fuel cell, DMFC)는 메탄올(에탄올,
아이소 프로판올, 포름산)을 직접 연료극에 공급하여 작 동시키는 연료전지로서 분해되면 물로 배출되어 자연 친 화적 에너지인 것을 볼 수 있다. (Fig. 1) 


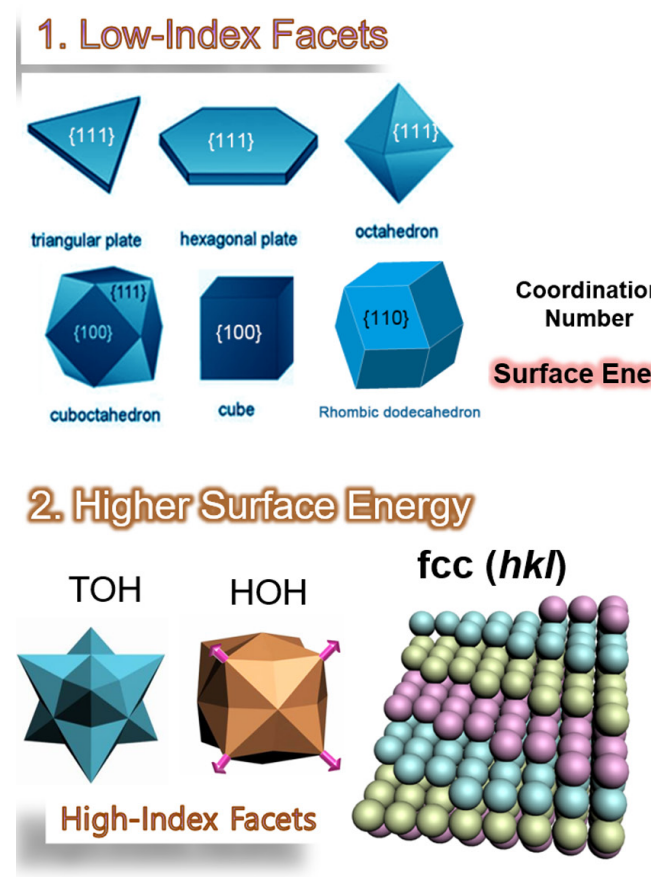

Fig. 3. 나노입자의 모양에 따른 결정면의 변화

또한, 연료공급 체계가 간단하여 시스템의 소형화 및 경량화가 가능한 장점이 있다. 그리고 $\mathrm{DMFCs}$ 는 이러한 장점으로 인하여 고압가스 형태의 수소사용, 공급, 저장 등의 인프라 구축이 어려운 독립형 전원 분야에 활용도가 매우 뛰어난 연료전지로 주목받고 있다. 현재 사용되는 전원이 배터리는 오랜 충전과 사용시간이 제한적인 단점 을 지니고 있다. 따라서 전원 공급이 이동 시 유용하며, 경량화 친환경화를 위해 개발하고 있으며, 이 연료전지의 내구성과 효율성을 높이기 위해 표면적이 큰 나노입자가 사용되고 있다. 특히 효율이 좋은 백금 나노입자가 사용 되고 있으며, 백금을 이용한 메탄올 분해과정에서 백금과 흡착성이 좋은 $\mathrm{CO}$ 가 생성되게 된다. ${ }^{6,7)}$ (Fig. 2) $\mathrm{CO}$ 가 흡 착되는 피독 현상은 촉매의 활성을 낮게 만들어 내구성이 좋지 않게 된다. 또한, 귀금속인 백금이 경제적인 측면에 서 비싼 가격 때문에, 이 백금 입자의 비율을 적게 하거나 $\mathrm{CO}$ 흡착을 약하게 하고, 전극 표면으로부터 $\mathrm{CO}$ 를 제거하 기 위한 노력을 하고 있다. 나노입자의 촉매 내구성과 효 율성을 증가시키기 위한 노력으로 나노입자의 모양을 조 절하면 모양에 따라 다른 결정면을 조절하고, 이 결정면 fcc (111) fcc (100) fcc (110)

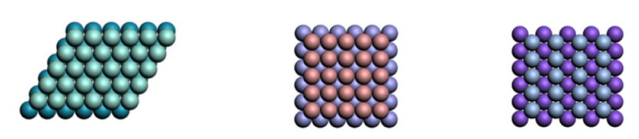

9

8

fcc $(111)<f c c(100)<$
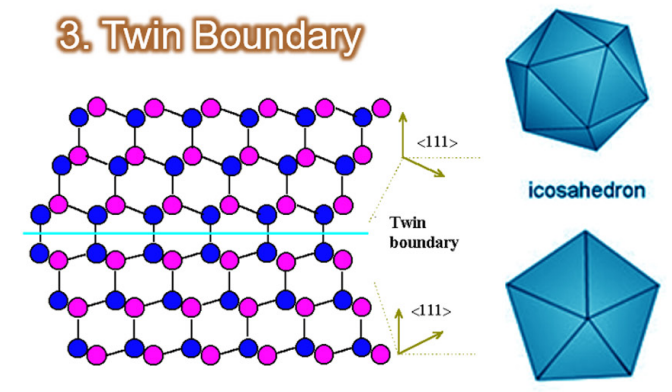

decahedron

들은 표면에너지가 달라 촉매의 활성도에 영향을 준다. ${ }^{8-}$ 12) 또한, 나노입자의 구조는 두 가지 세 가지 입자의 합금 이나 코어-셀 구조에 따라 다른 표면에너지를 가지고 있 다. ${ }^{13-17)}$ 그리고 피독 현상의 $\mathrm{CO}$ 흡착을 줄여주기 때문에 촉매 활성에 영향을 주게 된다.

나노입자는 넓은 표면적으로 활성은 뛰어나나 안정성 문제를 항상 지니고 있다. 이러한 안정성 증가하기 위해 나노입자의 지지체를 적용하게 되는데, 카본이나 그래 핀, 산화 금속물을 이용하게 된다. 그리고 이러한 구조적 모양, 합금과 담지체을 이용하여 나노입자를 합성한 다음 광-전기화학적을 같이 이용한 하이브리드 시스템이 최 근에는 연구되고 있다.

\section{2. 본론}

가. 나노입자는 표면에너지에 따라 촉매의 활성이 다르 게 나타난다. 촉매의 표면에너지를 조절하는 방법으로는 나노입자의 모양조절이 있다. 모양에 따라 다른 결정면을 지니기 때문에 촉매 활성이 다르게 나타난다. 면심입방격 


\section{특 집 ㅁㅃ 이영욱, 신태호}
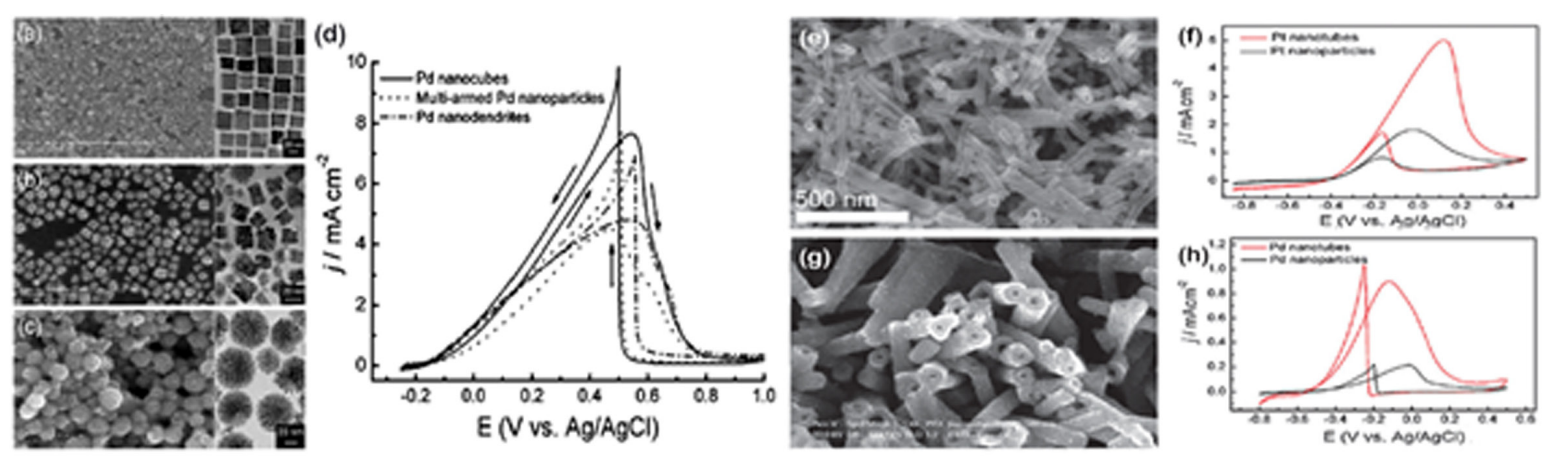

Fig. 4. 팔라듐 나노입자의 모양 a) 큐브, b) 멀티 암드, c) 덴드라이트 모양의 주사현미경 (SEM) 이미지 d) 전기화학적 특성. e,) 백금 나노튜 브, g) 팔라듐 나노튜브의 SEM 이미지와 f) 백금 나노튜브와 h) 팔라듐 나노입자의 전기화학적 특성 18.19)

자(FCC) 구조일 때 배위수가 낮을수록 표면에너지는 증 가하기 때문에 촉매 활성을 증가시킬 수 있다. 또한, 낮 은 지수 경계면이 쌓여 고 지수 경계면일 경우과 경계면 과 경계면이 만나 쌍둥이 경계면일 나타날 때 표면에너지 가 증가할 수 있다. 표면에너지의 증가는 전자의 이동이 빠르게 전개될 수 있으며, 이로써 촉매의 활성이 증가할 수 있다. (Fig. 3)

모양에 따른 팔라듐의 전기화학적 특성을 보면, 결정면 에 따라 전기화학적 활성도가 다르다는 것을 알 수 있다. 큐브 모양과 멀티 암드, 덴드라이트 모양의 3 가지 모양의 나노입자를 합성하여 전기화학적 특성을 측정한 결과 큐 브가 결정면이 111 을 가지는 두 가지의 입자보다 표면에 너지의 활성이 향상되어 전기화학적 활성이 뛰어나다는 것을 알 수 있다. 튜브 형태로 표면적을 크게 모양을 조 절하여 일반적인 백금과 팔라듐 나노입자와 비교 하였을 경우 활성이 뛰어나게 나타나는 것을 알 수 있다. ${ }^{18,19)}$ (Fig. 4)

나. 나노입자는 구조에 따라 전기화학적 촉매 활성이 다르다. 그 이유는 구조에 따라 표면에너지가 다르게 나 타나며, 또한 두 가지 세 가지 금속을 합금하면 일반적으 로 촉매로 상용되는 백금의 피독 현상을 줄일 수 있다. 백 금에 다른 금속을 결합하면 두 가지의 효과가 나타난다. 하나는 백금의 쉽게 흡착되는 $\mathrm{CO}$ 의 흡착 세기를 약하게 만들어 CO가 잘 제거 될 수 있는 electronc effect이며, 또 하나의 효과는 bifuntional effect인테 Pt에 흡착되는 $\mathrm{CO}$ 에 다른 금속의 $\mathrm{OH}$ 기가 $\mathrm{CO}$ 의 세기를 약하게 하며,

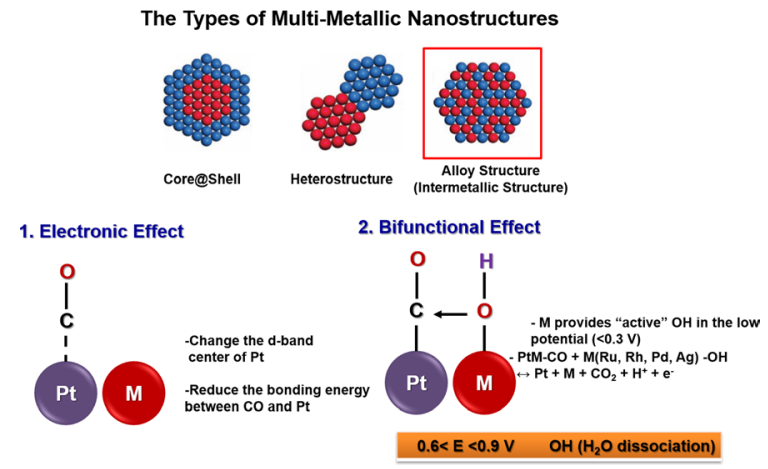

Fig. 5. 나노입자의 구조와 구조로 인한 두 가지 효과 ${ }^{22-25)}$

$\mathrm{CO}_{2}$ 로 제거되는 효과가 있기에 나노입자의 합금 구조를 만들어 $\mathrm{CO}$ 의 피독 현상을 줄여주는 촉매가 개발되고 있 다. ${ }^{21,21)}$ (Fig. 5)

일반적으로 골드 나노입자는 안정성에 단점이 있으며, 팔라듐 나노입자는 촉매반응에 장점이 있다. 그러나 골드 의 경우 촉매 반응성이 낮으며, 팔라듐의 경우 산화 반응 성이 있어 내구성에 단점이 있다. 이러한 보완점을 보완 하기 위해 두 가지 이상의 금속의 나노입자를 합성하는 연구가 진행되고 있다. Fig. 6을 보면 같은 모양과 크기 의 골드과 팔라듐, 골드-팔라듐 나노입자를 보면 위의 구조를 설명한 것처럼 합금 구조가 가장 전기화학적 특성 이 뛰어난 것을 알 수 있다. 그 이유는 팔라듐-골드의 구 조의 장점은 두 금속이 가지는 장점을 동시에 지니며, 알 콜 분해 반응 시 생기는 $\mathrm{CO}$ 의 흡착을 줄여 줄 수 있다. 또한, 골드와 팔라듐의 비율을 조절할 경우 비율에 따른 
(a)
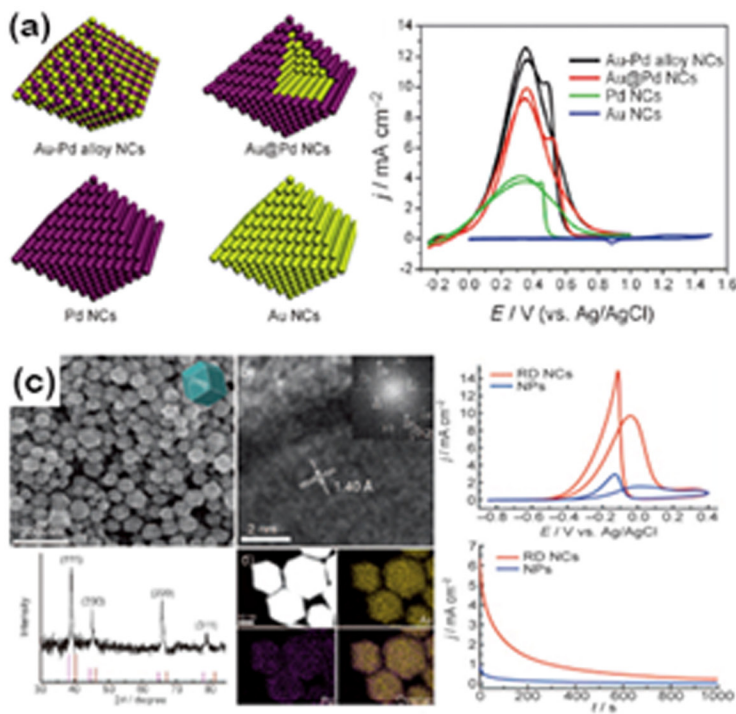
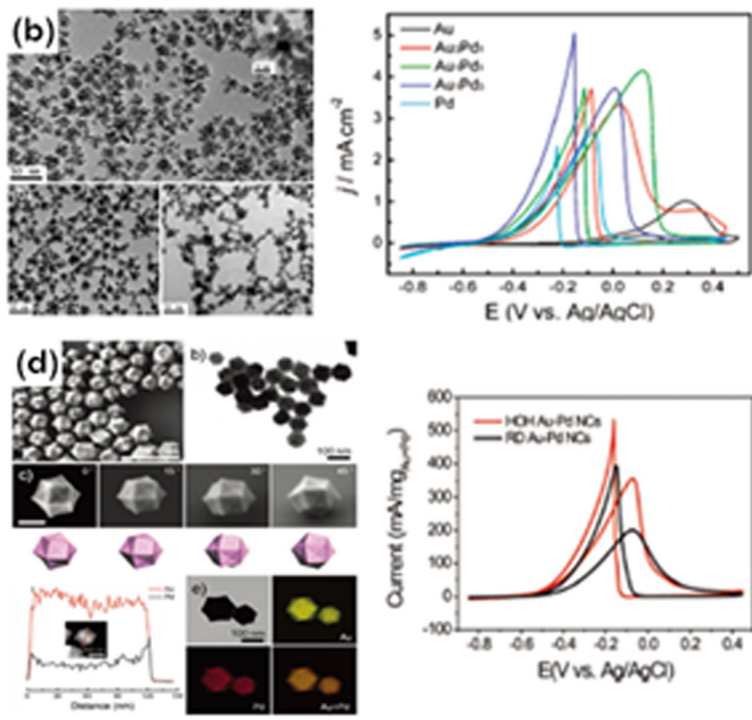

Fig. 6. a) 같은 모양의 골드와 팔라듐 골드-팔라듐 합금 나노입자의 전기화학적 특성 비교 b) 골드-팔라듐의 비율이 조절된 dendrites의 나 노입자의 전기화학적 특성 비교, c) 골드-팔라듐 (110) 경계면을 가지는 마름모형 나노입자와 골드-팔라듐 (111) 경계면 나노입자의 전 기화학적 특성 비교, d) 고 지수를 가지는 골드-팔라듐 나노입자와 마름모형 나노입자의 전기화학적 특성 22-25)

표면에너지가 틀리기 때문에 촉매의 활성을 증가할 수 있 다. 따라서 나노입자의 구조를 조절하면서 모양을 조절할 경우 같은 골드-팔라듐 나노입자일지라도 구조와 모양 을 같이 증가함으로 인해 전기화학적 활성을 증가할 수 있다. ${ }^{22-25)}$ (Fig. 6)
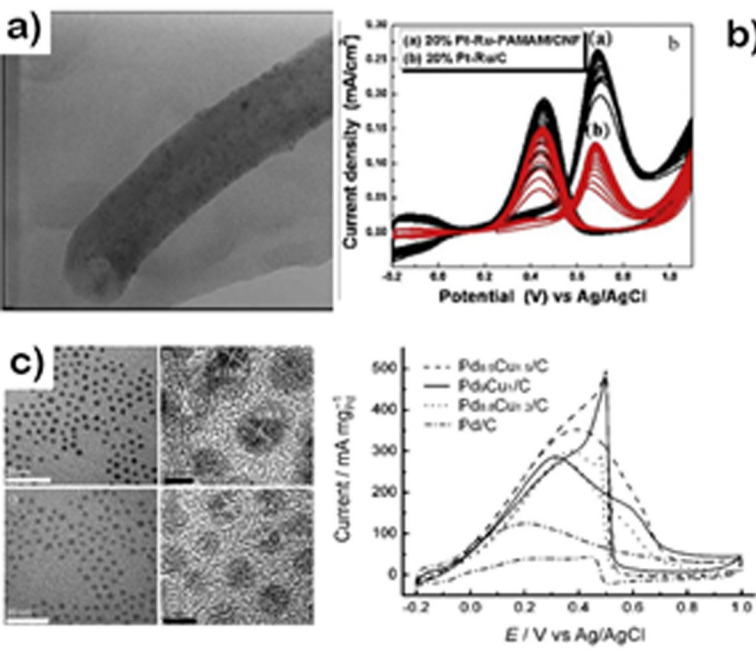

b)
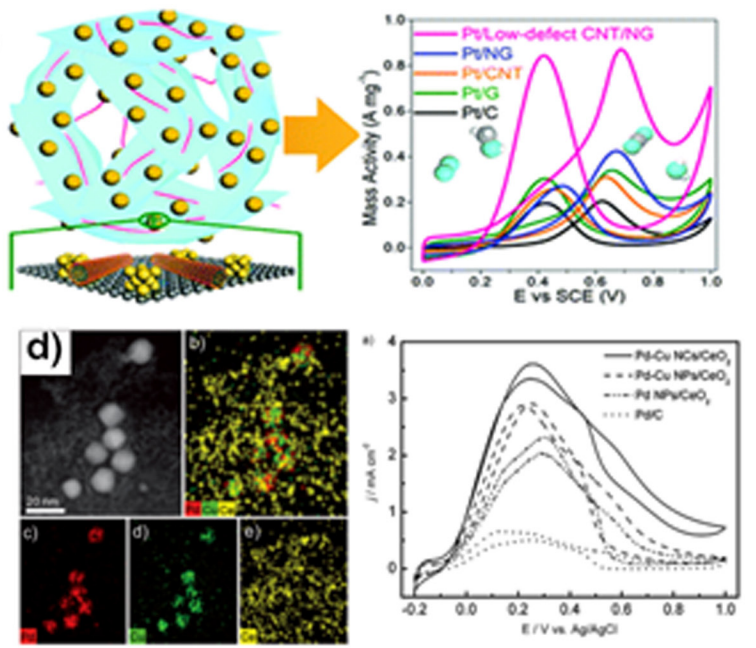

Fig. 7. a) 다공성 카본과 카본에 담지한 백금촉매의 전기화학적 특성, b) 그래핀과 탄소나노튜브 시스템에 담지한 백금촉매의 전기화학적 특 성, c) 카본에 담지한 합금 나노입자의 전기화학적 특성, d) 산화 세리아에 담지한 촉매의 전기화학적 특성 26-29) 

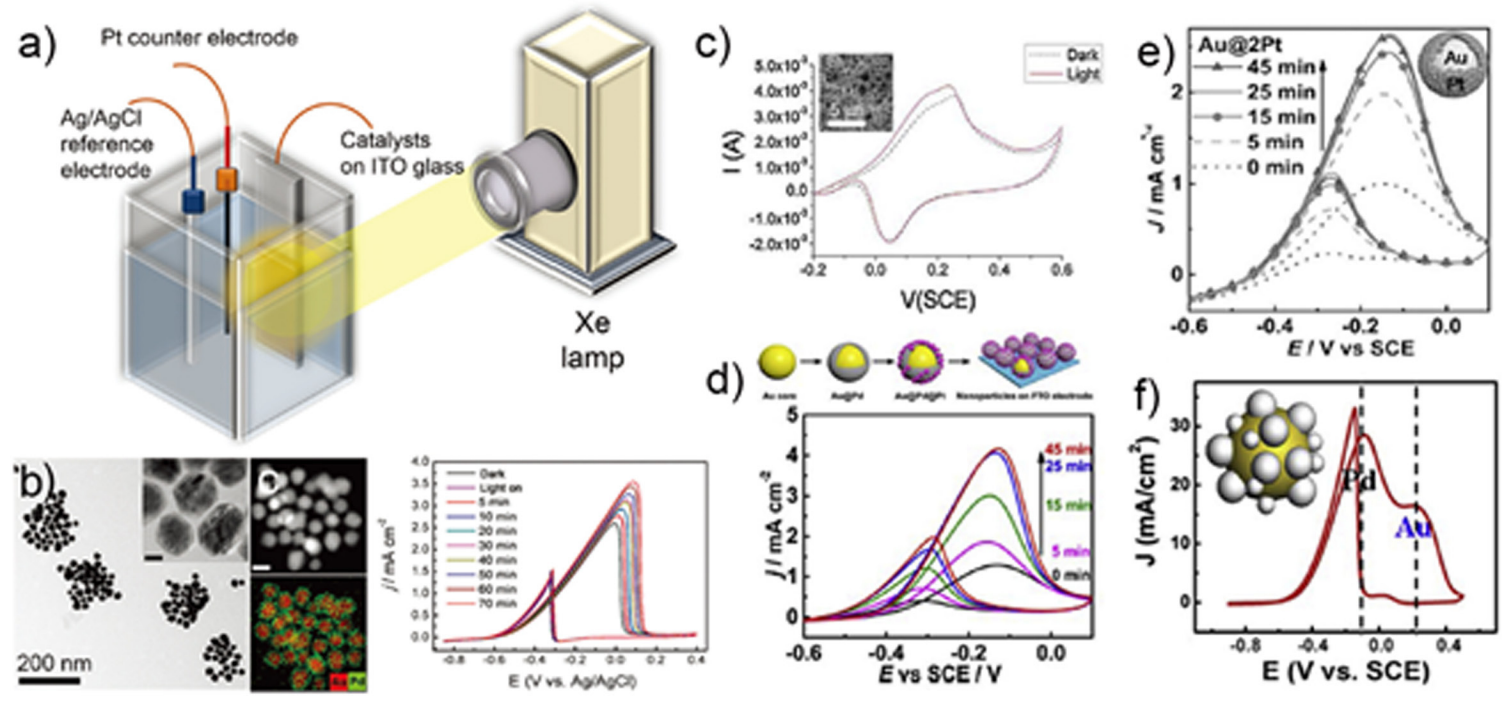

Fig. 8. a) 광학적-전기화학적 하이브리드 시스템, b) 골드@팔라듐 나노입자, c)골드 나노시트, d) 골드@팔라듐@백금 나노입자, e) 골드@백 금 나노입자, f)골드-팔라듐 헤테로 구조의 나노입자의 광학적-전기화학적 특성 ${ }^{30-34)}$

간의 표면에너지를 변화시켜 촉매의 활성을 증가시킬 수 있다. Fig. $7 \mathrm{a}$ 는 다공성 카본와 카본블랙에 나노입자를 담지하여 전기화학적 특성을 보았는데 표면적이 넓은 다 공성 카본 백금촉매가 전기화학 특성의 활성이 증가하는 것을 볼 수 있으며, 그래핀과 나노튜브의 담지체를 같이 사용하여 한 가지 담지체를 사용하였을 전자의 흐름을 증 대하여 촉매의 활성도가 증가하는 것을 알 수 있었다. ${ }^{26-}$ 27) (Fig. 7b)

카본에 두 가지 금속 입자를 담지한 경우, 상용화 촉매 보다 활성이 증대하는 것을 보았으며(Fig. 7c), 산화 세리 아를 담지체로 사용하여 일반적인 상용화 촉매보다 증대 하는 것을 볼 수 있다. 담지체의 영향에 따라 같은 촉매일 지라도 촉매의 활성이 증대할 수 있으며, 촉매와 담지체 에 사이의 표면에너지에 의해 촉매의 활성도를 증대할 수 있다. ${ }^{28-29)}$

라. 촉매의 광학적-전기화학적 하이브리드 시스템은 촉매의 구조가 중요하다. 촉매의 광학적 특성과 전기화학 적 특성이 다 존재하여야 하기에, 어떤 나노입자의 구조 를 선택하느냐가 중요하다. 일반적으로 모양이나 사이즈 에 따라 광학적 특성을 가지는 골드나 실버 입자가 필요 하며, 또한 전기화학적 특성으로 사용되는 백금과 팔라듐
금속이 필요하다. 이러한 두 금속의 합금은 광학적 특성 이 거의 나타나지 않기 때문에 단일 금속의 특성을 가지 기 위해 코어-셀이나 헤테로 구조를 일반적으로 선택하 게 된다. 물론 셀의 두께가 두꺼울 경우 광학적 특성이 점 점 사라지기 때문에 셀의 두께를 조절하는 것이 중요 요 소가 된다. Fig. $8 \mathrm{a}$ 를 보면 광학적-전기화학적 시스템의 도시화를 볼 수 있으며, Fig. 8b를 보면 골드@팔라듐 구 조를 광-전기화학적 하이브리드 방식을 측정한 결과 시 간에 따라 활성이 증가하는 것을 볼 수 있다. 이러한 이유 는 광학적 특성을 가지는 나노입자는 빛을 받아 촉매의 전자전달을 활성화하며, 그러한 영향을 주위의 전기화학 적 특성을 가지는 촉매에 영향을 주기 때문에 표면에너지 의 활성이 증대되어 촉매의 활성이 증대되게 된다. 물론 단일 금속의 골드나노시트로 광-전기화학적 실험을 한 결과 촉매 활성이 증대되는 것을 볼 수 있었지만, 기존의 백금이나 팔라듐 나노입자에 비교한 결과 활성은 낮은 것 으로 나타났지만 골드 시트가 확실히 광학적 특성으로 촉 매에 영향을 주는 것을 알 수 있었다. (Fig. 8c) 또한 골 드@팔라듐@백금과 골드@백금 나노입자일 경우 광학 성분을 주었을 경우 기존보다 촉매 활성이 증대하는 것을 볼 수 있었다. (Fig. 8d, 8e) 또한, 골드에 팔라듐을 담지 


\section{나노입자의 구조와 모양, 담지체 및 하이브리드 시스템 제어를 통한 직접메탄올 연료전지의 촉매 개발}

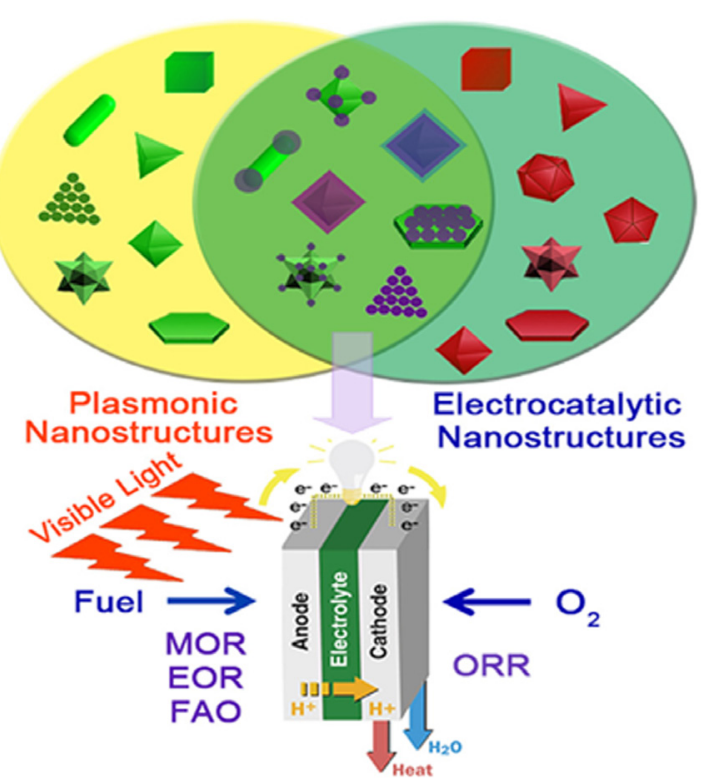

Fig. 9. 모양과 구조가 조절된 나노입자를 이용한 광-전기화학 시 스템 도시화 35

한 헤테로 구조인 나노입자 경우 두 가지 광학적, 전기화 학적 성질을 다 갖기 때문에 촉매의 활성이 증가하는 것 을 알 수 있었다. ${ }^{30-34)}$ (Fig. 8f)

\section{3. 결론}

$\mathrm{DMFCs}$ 반응에서 나노입자의 역할은 메탄올을 분해되 는 과정에서 나노입자에 흡착되는 $\mathrm{CO}$ 의 흡착 세기를 얼 마나 줄이면, 분산도를 높여 내구성을 증가시키고 표면에 너지를 조절하여 활성을 증가시키는 연구가 되고 있다. 나노입자 촉매의 내구성과 활성을 나노입자의 모양을 조 절하고, 구조를 변화시키고, 담지체를 이용하며, 광-전 기화학적 시스템의 연구 방식이 진행되고 있으며, 앞으로 구조와 담지체 광-전기화학적 특성을 동시에 가지는 나 노입자를 합성되어 촉매반응의 내구성과 활성도를 증가 시킬 것으로 전망한다. ${ }^{35)}$ (Fig. 9)

저자는 광-전기화학적 시스템의 촉매를 합성하기 위 해서는 촉매를 증가시킬 수 있는 담지체와 광학적 특성을 이용할 수 있는 촉매제, 나노입자의 모양과 구조를 동시 에 만족할 수 있는 촉매가 개발될 것으로 전망하며, 이러
한 촉매 개발은 연료전지의 효율성을 증대시켜, 일상의 우리 생활에 도움이 될 것으로 생각한다.

\section{참고문헌}

1. W. Huang, H. Wang, J. Zhou, J. Wang, P.N Duchesne, D. Muir, P. Zhang, N. Han, F. Zhao, M. Zeng, J. Zhong, C. Jin, Y. Li, S.-T. Lee, H. Dai, "Highly active and durable methanol oxidation electrocatalyst based on the synergy of platinumnickel hydroxideegrapheme,", Nat. Commun. 610035 (2015).

2. J. Xie, Q. Zhang, L. Gu, S. Xu, P. Wang, J. Liu, Y. Ding, Y.F. Yao, C. Nan, M. Zhao,Y. You, Z. Zou, "Ruthenium-platinum core-shell nanocatalysts with substantially enhanced activity and durability towards methanol oxidation," Nanomater. Energy 21 247-257 (2016).

3. B. Kakade, I. Patil, M. Lokanathan, A. Swami, "Enhanced methanol electrooxidation at Pt skin@ PdPt nanocrystals," J. Mater. Chem. A3 17771-17779 (2015).

4. W. Hong, C. Shang, J. Wang, E. Wang, "Bimetallic PdPt nanowire networks with enhanced electrocatalytic activity for ethylene glycol and glycerol oxidation," Energy Environ. Sci. 8 29102915(2015).

5. Y.-C. Shi, L.-P. Mei, A.-J. Wang, T. Yuan, S.-S. Chen, J.-J. Feng, "I-Glutamic acidassisted ecofriendly one-pot synthesis of sheet-assembled platinum-palladiumalloy networks for methanol oxidation and oxygen reduction reactions," J. Colloid Interface Sci. 504 363-370 (2017).

6. N. Jung, D. Y. Chung, J. Ryu, S. J. Yoo, Y. -E. Sung, "Pt-based Nanoarchitecture and Catalyst Design for Fuel Cell Applications," Nano Today 9 433-456 (2014).

7. Y. Liu, M. Chi, V. Mazumder, K. L. More, K. Soled, S.; Henao, J. D.; Sun, S. "Composition-Controlled Synthesis of Bimetallic PdPt Nanoparticles and Their Electro-oxidation of Methanol," Chem. Mater. 23 4199-4203 (2011).

8. Y. Xia, Y. Xiong, B. Lim, S. Skrabalak, E. "ShapeControlled Synthesis of Metal Nanocrystals: Simple Chemistry Meets Complex Physics?"Angew. Chem., Int. Ed. 48 60-103 (2009).

9. Z. Peng, H. Yang, "Designer Platinum Nanoparticles: 
Control of Shape, Composition in Alloy, Nanostructure and Electrocatalytic Property" Nano Today 4, 143164 (2009).

10. J. W. Hong, S. W. Kang, B-S. Choi, D. Kim, S. B. Lee, Han, S. W. "Controlled Synthesis of Pd-Pt Alloy Hollow Nanostructures with Enhanced Catalytic Activities for Oxygen Reduction," ACS Nano 6 24102419 (2012).

11. J. W. Hong, Y. Kim, Y. Kwon, S. W. Han, S. W. "Noble-Metal Nanocrystals with Controlled Facets for Electrocatalysis." Chem.-Asian J. 11, 2224-2239 (2016).

12. C. Li, T. Sato, Y. Yamauchi, "Electrochemical Synthesis of One-Dimensional Mesoporous Pt Nanorods Using the Assembly of Surfactant Micelles in Confined Space," Angew. Chem., Int. Ed. 52 80508053 (2013).

13. Y. Kim, Y. W. Lee, M. Kim, S. W. Han, "One-Pot Synthesis and Electrocatalytic Properties of Pd@Pt Core-Shell Nanocrystals with Tailored Morphologies," Chem. - Eur. J. 20 7901-7905(2014).

14. J. Zhang, K. Li, B. Zhang, "Synthesis of Dendritic $\mathrm{Pt}-\mathrm{Ni}-\mathrm{P}$ Alloy Nanoparticles with Enhanced Electrocatalytic Properties," Chem. Commun. 51, 12012-12015 (2015).

15. C. Li, Y. Yamauchi, Facile Solution Synthesis of Ag@ Pt Core-Shell Nanoparticles with Dendritic Pt Shells. Phys. Chem. Chem. Phys. 15 3490-3496 (2013).

16. M. Gong, G. Fu, Y. Chen, Y. Tang, T. Lu, "Autocatalysis and Selective Oxidative Etching Induced Synthesis of Platinum-Copper Bimetallic Alloy Nanodendrites Electrocatalysts," ACS Appl. Mater. Interfaces 6 7301-7308 (2014).

17. Z. Hang, Y. Yang, F. Nosheen, P. Wang, J. Zhang, J. Zhuang, X. Wang, "Synthesis of Dendritic Pt-Ni-P Alloy Nanoparticles with Enhanced Electrocatalytic Properties," Small 9 3063-3069 (2013).

18. Y. W. Lee, M. Kim, S. W. Han,"Shaping Pd nanocatalysts through the control of reaction sequence,"Chem. Commun. 46 1535-1537 (2010).

19. Y. W. Lee, M. A. Lim, M. S. W. Kang, S. I. Park, S. W. Han, "Facile Synthesis of Noble Metal Nanotubes by Using ZnO Nanowires as Sacrificial Scaffolds and Their Electrocatalytic Properties." Chem. Commun, 47 6299-6301 (2011).

20. K. Vinodgopal, J. Peller, O. Makogon, \& P. V. Kamat, (1998). "Ultrasonic mineralization of a reactive textile azo dye, remazol black B. Water research,”J. Phys.
Chem. 32, 3646-3650.

21. H. A. Gasteiger, N. Markovic, Jr. P. N. Ross \& E. J. Cairns, "Methanol electrooxidation on wellcharacterized platinum-ruthenium bulk alloys." J. Phys. Chem, 97, 12020-12029 (1993).

22. J. W. Hong, D. Kim, Y. W. Lee, M. Kim, S. W. Kang, S. W. Han, S "Atomic-distribution-dependent electrocatalytic activity of $\mathrm{Au}-\mathrm{Pd}$ bimetallic nanocrystals," Angew. Chem. Int. Ed. 50 8876-8880 (2011).

23. Y. W.Lee, M. Kim, Y. Kim, S. W. Kang, J. H. Lee, S. W. Han, S. W. "Synthesis and electrocatalytic activity of Au-Pdalloy nanodendritesfor ethanol oxidation," $J$. Phys. Chem. C114 7689-7693 (2010).

24. Y. W.Lee, M. Kim, S. W. Kang, S. W. Han, "Polyhedral bimetallic alloy nanocrystals exclusively bound by $\{110\}$ facets: Au - Pd rhombic dodecahedra," Angew. Chem. Int. Ed. 50 3466-3470 (2011)

25. Y. W. Lee, D. Kim, J. W. Hong, S. W. Kang, S. B. Lee,S. W. Han, "Kinetically Controlled Growth of Polyhedral Bimetallic Alloy Nanocrystals Exclusively Bound by High-Index Facets: Au - Pd Hexoctahedra," Small 9 660-665(2013).

26. T. Maiyalagan,"Pt-Ru nanoparticles supported PAMAM dendrimer functionalized carbon nanofiber composite catalysts and their application to methanol oxidation."J Solid State Electrochem 13 1561-1566 (2009).

27. M. Yan, Q. Jiang, T. Zhang, J. Wang, L. Yang, Z. $\mathrm{Lu}, \mathrm{H}$. Huang, "Three-dimensional low-defect carbon nanotube/nitrogen-doped graphene hybrid aerogel-supported Pt nanoparticles as efficient electrocatalysts toward the methanol oxidation reaction." J. Mater. Chem. A 6, 18165-18172 (2018).

28. K. H. Park, Y. W. Lee, S. W. Kang, S. W. Han, "A Facile One-Pot Synthesis and Enhanced Formic Acid Oxidation of Monodisperse $\mathrm{Pd}-\mathrm{Cu}$ Nanocatalysts," Chem. Asian, J. 6 1515-1519 (2011).

29. K. H. Park, Y. W. Lee, Y. Kim, S. W. Kang, S. W. Han, "One-Pot Synthesis of $\mathrm{CeO}_{2}-$ Supported Pd$\mathrm{Cu}$-Alloy Nanocubes with High Catalytic Activity." Chem. Eur. J., 19 8053-8057(2013).

30. S. Lee, Y. Wy, Y. W. Lee, K. Ham, S. W. Han, "Core-Shell Nanoparticle Clusters Enable Synergistic Integration of Plasmonic and Catalytic Functions in a Single Platform," Small 131701633 (2017).

31. C-T Lin, M-N Chang, H. J. Huang, C-H Chen, R-J Sun, B-H Liao, Y-FC Chau, C-N Hsiao, M-H Shiao, 
나노입자의 구조와 모양, 담지체 및 하이브리드 시스템 제어를 통한 직접메탄올 연료전지의 촉매 개발

F-G Tseng, "Rapid fabrication of three-dimensional gold dendritic nanoforests for visible light-enhanced methanol oxidation," Electrochim Acta 192 15 - 21(2016).

32. H. Yang, L. Q. He, Y. W. Hu, X. Lu, G. R. Li, B. Liu, B. Ren, Y. Tong, P. P. Fang "Quantitative detection of photothermal and photoelectrocatalytic effects Induced by SPR from Au@Pt nanoparticles," Angew Chem Int Ed. 12711624 - 11628 (2015).

33. H. Yang, L-Q. He, Z-H. Wang, Y-Y. Zheng, X. Lu, G-R. Li, P-P. Fang, J. Chen, Y. Tong "Surface plasmon resonance promoted photoelectrocatalyst by visible light from $\mathrm{Au}$ core $\mathrm{Pd}$ shell $\mathrm{Pt}$ cluster nanoparticles," Electrochim Acta 209 591 - 598(2016).

34. Q. Wang, W. Zheng, H. Chen, B. Zhang, D. Su, X. Cui, "Plasmonic-induced inhibition and enhancement of the electrocatalytic activity of $\mathrm{Pd}-\mathrm{Au}$ heteronanoraspberries for ethanol oxidation," J. Power. Sources. 31629 - 36(2016).

35. S. Lee, Y. W. Lee, H. Ahn, J. H. Kim, S. W. Han,"Plasmon-enhanced electrocatalysis from synergistic hybrids of noble metal nanocrystals," Curr. Opin. Electrochem. 4 11-17(2017).
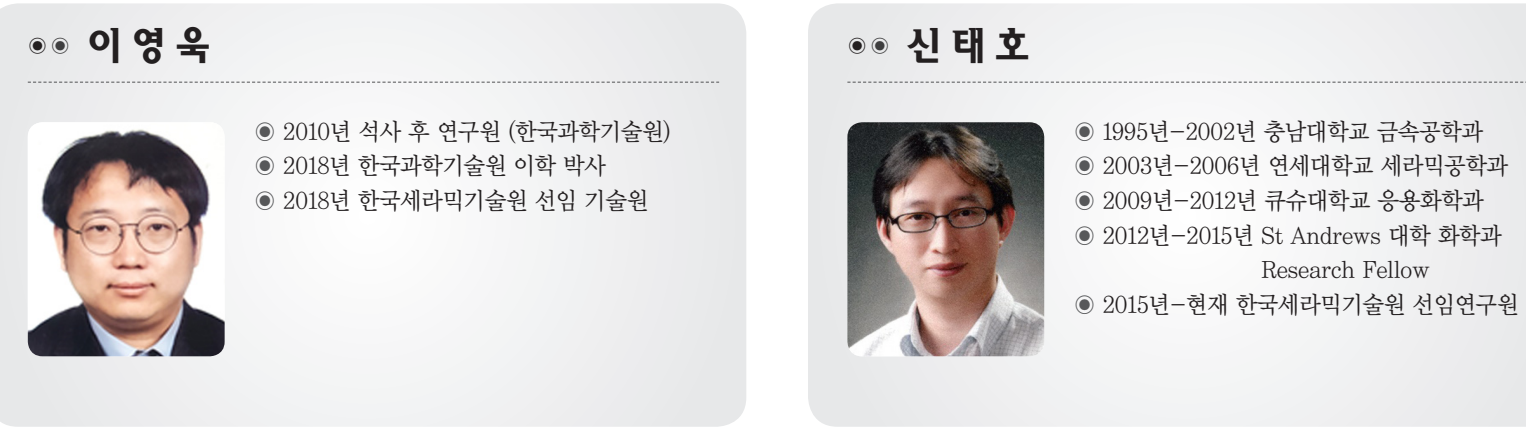